\title{
VII.-On the Geology of Rio de Janeiro.
}

By Arexander CALDCleUgh, Esq. M.G.S.

\author{
[Read 6th June, 1823.]
}

THE specimens which I have now the honour of presenting to the Geological Society were collected in the neighbourhood of Rio de Janeiro, a spot so long celebrated for the beauty of its surrounding scenery. The Bay running in the direction of north and south, and extending nearly thirty miles into the interior, stands perhaps unrivalled, whether viewed as a resort for shipping, or as merely affording a fit subject for the painter. It is surrounded by conical hills, which in one instance only (the Corcovado) exceed nine hundred or a thousand feet in height, and preserve the rounded character of gneiss, which is peculiar to this rock even in Europe, where the agents of destruction are feeble compared with those of a tropical country. Many of these hills are perfectly bare, while others are clothed to their summits with the most luxuriant vegetation. In some spots they rise abruptly from the sea, in others a small intermediate space is left. Wherever any soil is deposited by the heavy periodical rains, a thick plica of vegetation springs up, which in several instances prevents an examination of the subjacent strata.

The alluvial soil is mostly of a yellow or red colour; the latter variety is frequently washed by the children of the place for the minute portion of gold which it is known to contain. In making any excavation through the loose soil on the surface, regular layers of crystals of feldspar and pieces of quartz are met with, and with no appearance of having been transported thither. I am inclined to suppose that much of the superficial soil proceeded from a decomposition in situ, rather than from any washing down from the hills. On the shore the sand is of a brilliant white colour, and I think there are appearances to justify the idea that the sea has retired from this part of the coast.

The district which has fallen under my examination is confined to the immediate neighbourhood of the city of Rio de Janeiro, situate on the left or west side of the harbour.

The substance of which the mass of the mountains is composed, is gneiss ; granite in no instance constitutes a distinct formation. The numerous quar- 
ries close to the city afford great varieties of the former rock. Although its fitness as a building-stone varies considerably, it did not appear that a preference existed in favour of any particular quarry. Proximity seemed the main object. These excavations presented favourable opportunities for observing the stratification.

The leading direction of the gneiss appeared to be N.N.W. or N.W., and the dip varied considerably; in one case it was as much as $46^{\circ}$, in others merely a gentle inclination. The strata in one quarry were disturbed and contorted in a most singular manner without the disturbing cause being apparent.

This gneiss formation is all more or less intersected by granite veins, varying in thickness from two or three feet to as many inches. Some of the veins were stained with oxide of iron which had extended to some distance in the walls of the mass of gneiss. There was nothing to lead to a supposition that they were formed anterior or posterior to the mass which they intersected. From the mutual intersection of the crystallization, one would be rather led to infer, at least in some instances, that they were contemporaneous.

The only superjacent beds I met with were one of greenstone near the Valongo, and one of clay iron-stone near the Queen's House. The gneiss, although in some spots resembling a micaceous slate, speedily recovered its former aspect.

The greenstone bed in the gneiss at the Valongo was about twelve feet thick, dipping $35^{\circ}$ in the direction of S.S.E., the rock on which it rested having a slight dip to the N.W. This bed is of inconsiderable extent, and is formed of globular distinct concretions, which on being struck with the hammer separated in successive coatings abounding in oxide of iron.

The clay iron stone rested on the gneiss in very considerable thickness, but the nature of the ground and the proximity of the Queen's residence prevented a complete examination*.

The elevated peak called the Corcovado is situate on the Botafogo side of the city, and rises 2100 English feet above the level of the sea. The summit, composed of coarse porphyritic gneiss, of a hardness superior to that forming the mass of the hills below, is intersected by veins of quartz and felspar $\downarrow$.

In the gneiss of Rio de Janeiro, a great proportion of which may be termed porphyritic, the beauty and variety of the felspar is very striking. Some of the specimens of this mineral even approach to the moonstone of Ceylon, and others would no doubt furnish excellent kaolin. The decomposing variety is used by the lapidaries of the city to give a polish to amethysts. In

* The specimen, No. 37, is from this bed.

+ The large macle of felspar, No: 34 , is frem this locality. 
Mr. Catdcleugh on the Geology of Rio de Janeito.

some of the beds of gneiss near the sea shore, the crystals of felspar project considerably, and appear to have alone withstood the action of the elements. Some of the masses fallen into the sea appear perfectly fresh until on attempting to stand upon them, the foot sinks into a mass of clay. The felspar is mostly in macled crystals.

A large proportion of the quartz met with in the neighbourhood of Rio de Janeiro, is of that variety termed slaty and ferruginous. It is by no means unusual to meet large boulders containing beautiful crystals of dark brown mica, of the primitive form.

The specimen of granite from a drusy vein in gneiss at the Valongo contains mica and quartz distinctly crystallized.

The simple minerals in the gneiss in this neighbourhood are by no means abundant. I met with the following:

Hornblende.

Yellow carbonate of lime, disseminated.

Phosphate of lime, amorphous of a deep bottle green.

The crystallized variety of the foregoing (Apatite).

Garnets, all of some tinge of red, and varying considerably in size.

Sulphuret of ition, abundant in the quarry of St. Cristovan.

Sulphuret of arsenic.

Chlorite, disseminated and lamellar.

With the exception of the garnet, which is more abundant in the gneiss, the other minerals were all taken from granite veins.

In Europe so large a district of gneiss would have afforded in all probability metalliferous beds or veins of considerable richness; but in Brazil it is only after leaving this formation, and falling in with the slates of the upper country, that any ores of consequence are to be discovered.

The following figure represents a case of frequent occurrence, of a bed of gneiss placed unconformably to those of the same rock on which it lies.

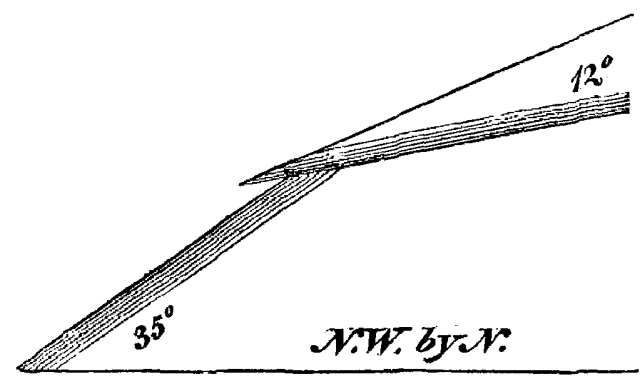

It often happens under these circumstances, that from the decomposition of the lower bed a hollow is formed by the overhanging of the upper; and I ob- 
tained from such a situation, the specimens of siliceous stalactite which are now sent to the Society.

At the point of junction of the two beds of gneiss these siliceous stalactites are in great abundance.

The absence of hot springs makes the occurrence of these stalactites of very considerable interest; and I cannot avoid offering an hypothesis to explain their formation. In Brazil there is constantly a trickling of water down the bare sides of the hills, which from evident causes acquires a very considerable increase of temperature. From having crawled through these little rills on my hands and knees, I can give a pretty correct idea of their temperature, which often reaches $140^{\circ}$ or $150^{\circ}$ of Fahrenheit. This warm water descending on decomposing strata of gneiss, such as is the case with that from which these specimens are taken, seizes the potash of the felspar, and then acts upon the quartz; and the water evaporating, deposits the silex in the form of a stalactite. Some of the hot springs or geysers of Iceland, which form the stalactite, do not reach the point of boiling; and perhaps the quantity of silex dissolved, (the inverse of what is shown to be the case with carbonate of lime,) may in a great measure depend on the temperature of the alkaline solvent. I do not know whether the presence of potash in these specimens confirms this conjecture. In some specimens the points are perfectly opaque, but the base puts on a hornstone appearance.

With the exception of the specimens from warm springs, recent siliceous formations are comparatively scarce, but by no means unknown. If, however, the more frequent occurrence of siliceous stalactite is to be looked for, it may probably be in warm countries, where the agents of destruction and reproduction are more active than in the colder climates of Europe. 